\title{
E-Learning Effectiveness Analysis in Developing Countries: East Nusa Tenggara, Indonesia Perspective
}

\author{
Sfenrianto Sfenrianto ${ }^{1}$, Ellen Tantrisna ${ }^{2}$, Habibullah Akbar $^{3}$, Mochamad Wahyudi ${ }^{4}$ \\ ${ }^{1}$ Information Systems Management Department, BINUS Graduate Program-Master of Information Systems \\ Management, Bina Nusantara University, Jakarta 11480, Indonesia \\ ${ }^{2}$ Sekolah Tinggi Kesehatan Citra Mandiri Husada, Kupang, East Nusa Tenggara 85228, Indonesia \\ ${ }^{3}$ Computer Science Department, BINUS Graduate Program-Master of Computer Science, \\ Bina Nusantara University, Jakarta 11480, Indonesia \\ ${ }^{4}$ Master of Computer Science-Postgraduate Programs STMIK Nusa Mandiri Jakarta 10450, Indonesia
}

\begin{tabular}{|c|c|}
\hline Article Info & ABSTRACT \\
\hline Article history: & The adoption of e-learning in developing countries like Indonesian \\
\hline & Universities have been focused in urban areas like the big cities, especially in \\
\hline Received Sep 26, 2017 & Java island. There is a lack of development of e-learning in a remote city like \\
\hline Revised Jul 11, 2018 & Kupang East Nusa Tenggara Indonesia which is located far away from the \\
\hline Accepted Aug 10, 2018 & $\begin{array}{l}\text { capital city. This research aims to assess the effectiveness of e-learning by } \\
\text { analyzing three factors in one of the higher institution in Kupang city, i.e. }\end{array}$ \\
\hline Keywords: & $\begin{array}{l}\text { Sekolah Tinggi Kesehatan Citra Mandiri Husada Kupang (STIKes CHMK). } \\
\text { The factors include culture, technology and infrastructure, and content }\end{array}$ \\
\hline Developing country & satisfaction. The data were collected using questionnaires. Research shows \\
\hline Effectiveness analysis & that with proper preparation for e-learning, the acceptance of e-learning in \\
\hline E-Learning & rural areas is significantly high. This finding suggests that e-learning can \\
\hline Indonesia perspective & greatry benerit the students ine Kupang city in developing countries. \\
\hline Learning management system & $\begin{array}{r}\text { Copyright }\left(\begin{array}{l}2018 \text { Institute of Advanced Engineering and Science. } \\
\text { All rights reserved. }\end{array}\right.\end{array}$ \\
\hline
\end{tabular}

\section{Corresponding Author:}

Sfenrianto Sfenrianto,

Information Systems Management Department,

BINUS Graduate Program - Master of Information Systems Management,

Bina Nusantara University, Jakarta, 11480, Indonesia.

Email: sfenrianto@binus.edu

\section{INTRODUCTION}

East Nusa Tenggara is one of the unique provinces in Indonesia. It has almost 2000 islands, including Flores, Sumba, and West Timor. East Nusa Tenggara is one of the poorest provinces in Indonesia due to the high unemployment rate (30\%), a high number of poor people ( $\$ 20$ per person per month), food shortage, and half of the children populations are undernutrition. One the reason of this situation is because East Nusa Tenggara is a rather isolated area for which it is underdeveloped due to poor infrastructure, health facilities, and education access. Similar pattern can also be found in other developing countries like Vietnam, and Timor Leste.

The education level for basic education graduates reached 61.94 percent, secondary (middle and high school) reached about 32.55 percent, and graduates of higher education (universities and colleges) are less than 10 percent of the total working-age population [1]. This number seems to be unrealistic to believe and it posits a huge challenge for the traditional school system due to the socio-economic, cultural and Geographic's backgrounds.

The development of science and technology today, especially in the information technology make the world of education continues to grow. Utilization of internet services in the education sector is also growing and even makes it easy for users to access information that provides learning content every time. Online learning system or commonly called e-learning is more often used by educational institutions which 
are already using internet facilities, to support teaching and learning process [2]. E-learning has been proven to be able to leverage distance education for remote areas with which using multimedia modalities via internet. The aim of this system is to expand access to education to the general public. Ease of access to elearning without face to face and not bound by time make online learning system implemented at several universities. Currently, e-learning concept has been widely accepted by the community, as proven by the many implementations of e-learning in educational institutions (schools, courses, and even universities).

E-learning can be used to help dynamic and flexible learning process between learners and lecturers [3]. It usually is implemented as a learning management system (LMS), a web application that controls the learning process (materials, forums, and evaluation) [4-5]. There are lots of available LMS in the market, made by various private and public companies such as ATutor, WebCity, Blackboard, Dekeos, ILIAS, Moodle, Sakai, and Edmodo. Among this platform, Edmodo gains popularity as 'The Top Apps for Teachers' which has more than 50 million users all over the world. Some previous researches on the effectiveness of Edmodo are available in [6-7].

The implementation of e-learning is not as easy as it seems. There are lots of factors such as culture [8], technology infrastructure, and learning materials [9]. The condition of the society at a given place determines the success of e-learning implementation. Different countries have unique culture; therefore, they have different level in accepting distant learning [8]. For an urban area like Jakarta, the people are familiar with the internet, and thus they can easily adopt distance learning. Indeed, some universities like Open University, Bina Nusantara University, and University of Indonesia already adopt the distance learning. However, for rural areas like Kupang, the adoption of e-learning is a new way of studying and could be very difficult for them.

This situation leads us to other problem i.e. the technology and infrastructure factor. Without proper infrastructures like internet access and the availability of lecturers, also greatly affect the effectiveness of the implementation of e-Learning [10-11].

Moreover, the delivery of content via e-learning also needs to be packaged in a form that can be easily understood by the students. Some studies have reported that good content can improve the satisfaction of students [12-13], improve learning process, and knowledge ability [14]. Therefore the students are motivated to learn through distant learning.

This study aims to improve the quality of education in Kupang city through the adoption of distance learning. The main problem in this research is "the analysis of aspects of cultural, technology-infrastructure, and content satisfaction regarding to e-learning implementation in Sekolah Tinggi Kesehatan Citra Mandiri Husada Kupang (STIKes CHMK), Kupang city". The answer is found by developing and providing elearning system in the STIKes CHMK.

We expect the new kind of education can lessen the barriers for the students to afford advanced education. The implementation of e-learning is held STIKes CHMK. The institution is a relatively new private institution which established in 2008 in the medical sector. STIKes CHMK is expected to support and to improve the quality of education in the almost-isolated area in Indonesia. Despite the lack of attention from the government as mentioned above, Kupang has begun to open up access to the application of ICT in teaching and learning. Therefore, this study focuses on analysis the effectiveness of the implementation of elearning in STIKes CHMK, in order to developing countries.

There have been several studies with regards to factors that influence e-learning effectiveness. For science education before college level like $\mathrm{K}-12$, in study [15] found four critical factors that affect the effectiveness of e-learning solution. These factors are support, resources, the individuals' motivation, and prior experience in using the solution. The focused of the study more on technological infrastructure (time and technology) as very important for developing countries.

A more rigorous study was performed for university level in some countries. For example, a study was conducted by electronically distributed questionnaire to 397 students public universities and private universities in a European country. The students have used e-learning systems platforms for the autumn semester of 2014. The author found that the e-learning effectiveness were influenced by students culture factor [16]. Similar factors were also observed in developing and in-conflict country, like Palestine [17]. This study have investigated the factors that affect e-learning effectiveness at Al-Quds Open University In Palestine. It found that instructor characteristics, student characteristics, technology, and impediments have strong relationships with e-learning effectiveness. In this study also able to show the importance of culture and technological infrastructure. Another study has also been done in Indonesia for effectiveness e-Learning [18]. This study focused on usability aspects Student Centered e-Learning Environment (SCeLE). The SCeLE is a learning management system based on Moodle, implemented at Faculty of Computer Science, Universitas Indonesia. However, all of these studies failed to highlight the importance of content analysis. In fact, content is also importance because students might feel bored and become frustated if they do not understand the materials. 
Thus, It is important to ensure whether an e-Learning effectiveness analysis in developing countries are through analyzing of factors such as: culture, technology and infrastructure, and content satisfaction. It will academic contribution on previous studies.

\section{RESEARCH METHOD}

The methodology used in this study was based on qualitative descriptive approach. The effectiveness analysis can be measured using either qualitative, quantitative, or both. In one study in [15] evaluate 63 abstracts based on their research design and found that 37 studies used quantitative. 5 used qualitative, and 9 used mixed method. It is clearly evident that quantitative is more popular due to more easier analysis, especially when tools are available.

The study of the analysis of e-learning effectiveness for developing countries has been done based on quantitative analysis to find out the factor that affects e-learning effectiveness at Al-Quds Open University In Palestine [17]. In addition to analysis, descriptive statistics have also been used for case studies in developing countries. For example the descriptive statistics (frequency and percent) can be used to find out the class category that has been influenced the effectiveness analysis of e-learning [19]. Another study in Indonesia for effectiveness e-Learning also analyzed using qualitative descriptive statistics [18].

The research framework is given in Figure 1. The first step is to analyze the requirement for the elearning system. The LMS is developed using based on Edmodo. The effectiveness and performance of the LMS are evaluated based on questioner and assessment evaluation of the students.

\section{Requirement Analysis}

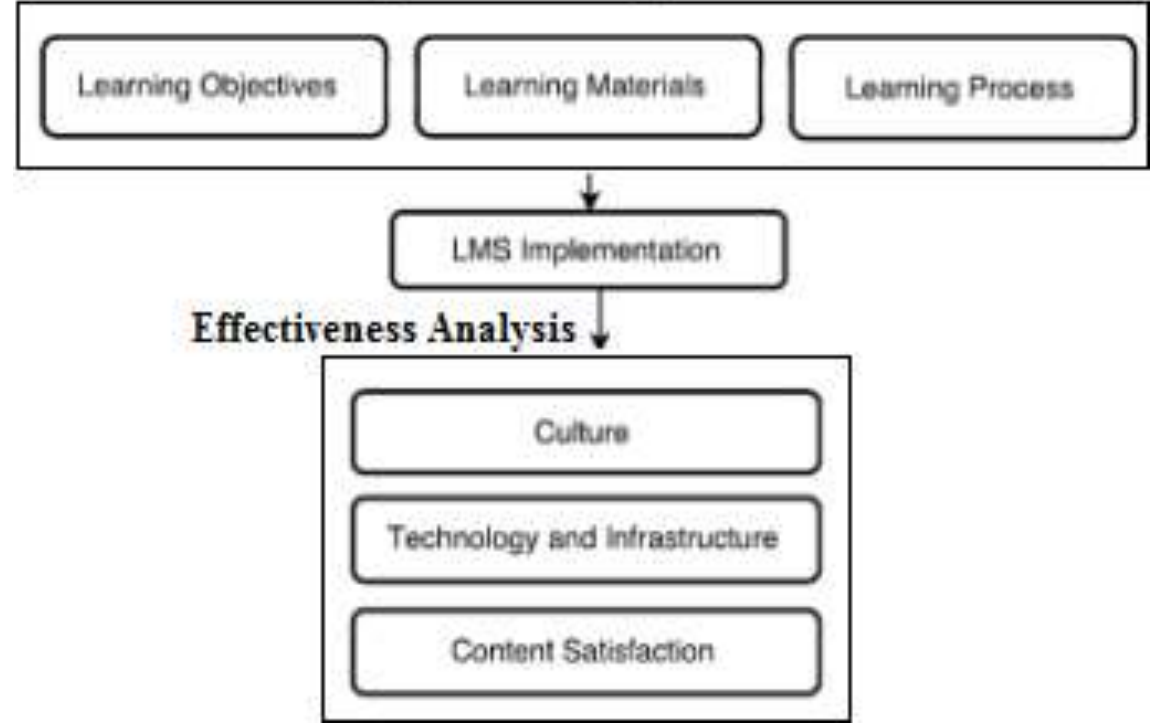

Figure 1. Research framework

\subsection{Requirement Analysis}

The research process begins with the requirement analysis of the e-learning including learning objectives, content, and learning processes. The learning objectives are to enhance computer literacy skills for students including basic computer knowledge, writing, making tables and figures, presentation, and database.

The learning materials are given in the table. The materials include the basic of computer, windows, office, word, access, power point, and excel. Each material is supported by presentation slide and lecture note. The learning material includes presentation slides and lecture notes containing computer literacy skill subjects as given in Table 1. Then, Table 2 shown The learning process section records the attendance of the student, discussion forums, assignments, and quizzes. 
Table 1. Learning Materials

\begin{tabular}{lcc}
\hline \multirow{2}{*}{ Topic } & \multicolumn{2}{c}{ Learning Materials } \\
\cline { 2 - 3 } & $\begin{array}{c}\text { Presentation } \\
\text { Slides }\end{array}$ & $\begin{array}{c}\text { Lecture Notes } \\
\text { (pdf/doc) }\end{array}$ \\
\hline Basic Computer & $\mathrm{X}$ & - \\
Basic Windows & $\mathrm{X}$ & - \\
Basic Microsoft Office & $\mathrm{X}$ & $\mathrm{X}$ \\
Microsoft Word & $\mathrm{X}$ & $\mathrm{X}$ \\
Microsoft Access & - & $\mathrm{X}$ \\
Microsoft Power Point & - & $\mathrm{X}$ \\
Microsoft Excel & $\mathrm{X}$ & $\mathrm{X}$ \\
\hline
\end{tabular}

Table 2. Learning Process

\begin{tabular}{lcccc}
\hline \multirow{2}{*}{ Topic } & Learning & \multicolumn{3}{c}{ Type of Process } \\
\cline { 3 - 5 } & Method & Quiz & Assignment & Material \\
\hline Basic Computer & F2F \& Online & F2F & Online & Online \\
Basic Windows & F2F \& Online & F2F & Online & Online \\
Basic Microsoft Office & F2F & F2F & - & Online \\
Microsoft Word & F2F \& Online & - & Online & Online \\
Microsoft Access & F2F & - & - & - \\
Microsoft Power Point & F2F \& Online & - & Online & Online \\
Microsoft Excel & F2F \& Online & - & Online & Online \\
\hline
\end{tabular}

\subsection{Implementation of the Learning Management Systems}

The evaluation process is given by distributing questionnaires to students of S1-Nursing 52 students from the 3 departments of obstetrics, nursing, and pharmacy. For the implementation, we used Edmodo Learning Management System, a social learning platform developed specifically for academia. The customized user interface is given in Figure 2.

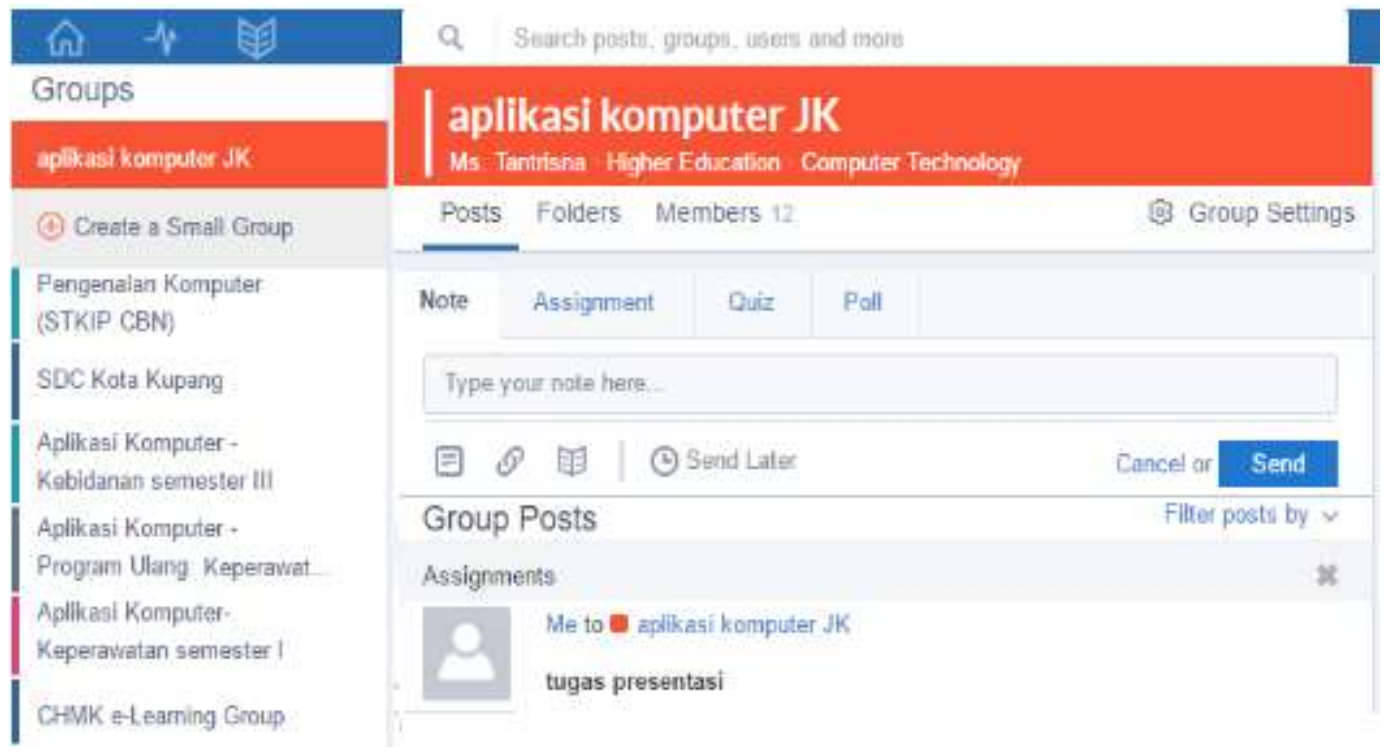

Figure 2. The Edmodo user interface (source: www.edmodo.com)

Edmodo enables the lecturers and students to share learning materials, links, and documents which can be accessed through aweb browser, iOS, and Android. There are four main features for the learning activities in the Edmodo interface: library, assignments, forum discussion, and grade book. In the library section, lecturers can access, download, upload, delete the learning materials including presentation slides, lecture notes, and web links. In the assignment section, the lecturers and students can access, download, and upload the assignments. In the forum discussion section, lecturers and students can send messages, attach files, and do discussion group. 
For marking the assignments, the lecturers can use the gradebook section. This feature is used to record of student grades in which lecturers can manually or automatically do thescoring. In this feature, lecturers can also manage the entire student learning outcomes assessment, such as the maximum value in each subject value. However, the quiz is done outside the LMS by using theface-to-face (F2F) method.

\subsection{Effectiveness Analysis}

The effectiveness of e-learning systems involve any factors that encourage students to use the system [20].To analyze the effectiveness of the proposed LMS, we determine three critical parameters including culture, technology and infrastructure, and content satisfaction, similar to factors used in previous studies [15-17]. These factors were selected because it is the most important factors which is the main concern for Indonesian education.

To evaluate the culture, the questions include three variables: learning process, learning style improvement, and the interaction with the lecture. To evaluate the technology and infrastructure, there are two variables: internet access, infrastructure. To evaluate the content satisfaction, we use six variables including usability, learning materials, user-friendly, suggestion, using frequency, support.

\section{RESULTS AND ANALYSIS}

The results from distributing questionnaires is explained in the following sections. Edmodo only as a complement beside classroom learning, the questionnaires were distributed only to students and some lecturers who have started using Edmodo as one additional facility of learning. Figure 3 shows profile of students who gave back the form is given as follows: 35 nursing students (12 men and 23 women).

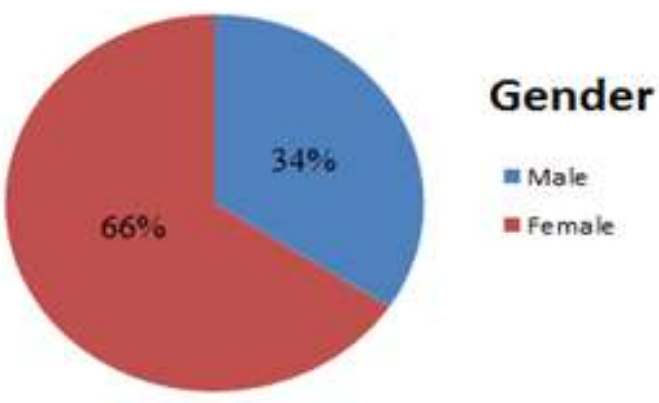

Figure 3. Nursing students profile

\subsection{Culture Analysis}

To evaluate the culture, the questions include There are three evaluated aspects in the questioners including: C1-The system usability for the student; C2-The student motivation to use the system; C3-The interaction between the students and lecturers. Figure 4 shows graph of culture analysis.

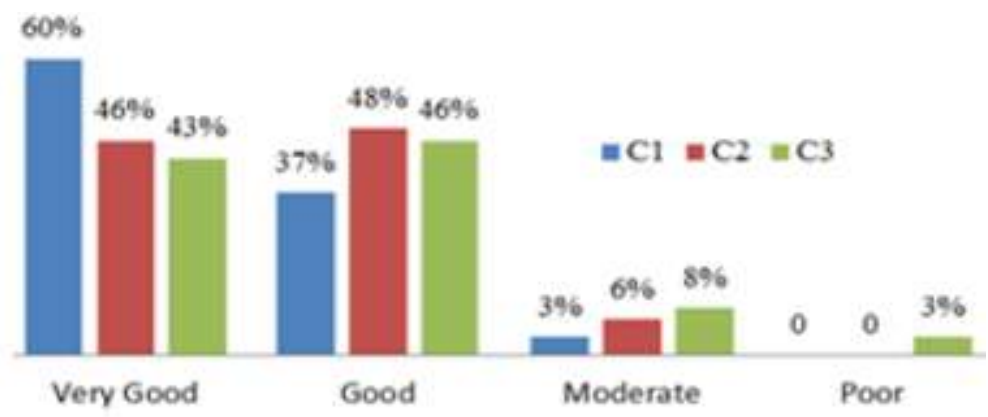

Figure 4. Culture analysis 
Firstly, the survey showed that 21 students (60\%), 13 students (37\%), 1 student (3\%) stated that the system usability for the student was very good, good, and moderate respectively. The reason is because the students do not have to go to the campus.

Secondly, the survey showed that 16 students (46\%)and 17 students $(48 \%)$ stated that the effect of e-learning (Edmodo) in the motivation of student learning was very good and good respectively. Only 2 students $(6 \%)$ choose moderate.

Finally, the survey showed that 15 students (43\%) and 16 students (46\%) stated that they have very good and good interaction with the lecturers respectively while 3 students $(8 \%)$ reported moderate interaction. However, there is 1 student reported poor interaction with the lecturers. The students were satisfied with the lecturers because they can easily ask the lecturers through the system. The student who has poor interaction with the lecturers maybe feel shy to ask lecturers.

These evaluation results indicated that most students in STIKes CHMK were able to use the elearning system with ease for assignment, downloading learning material, and discuss in the forum. The students' acceptance for a new kind of learning system was high.

\subsection{Technology and Infrastructure Analysis}

To evaluate the Technology and Infrastructure Analysis, there are five evaluated aspects in the questioners including: TI1-Access to the internet; TI2-The Access to the system; TI3-The availability of lecturers that supports e-learning system; TI4-availability of e-learning materials, presentations and lecture notes. Figure 5 shows graph of technology and infrastructure analysis.

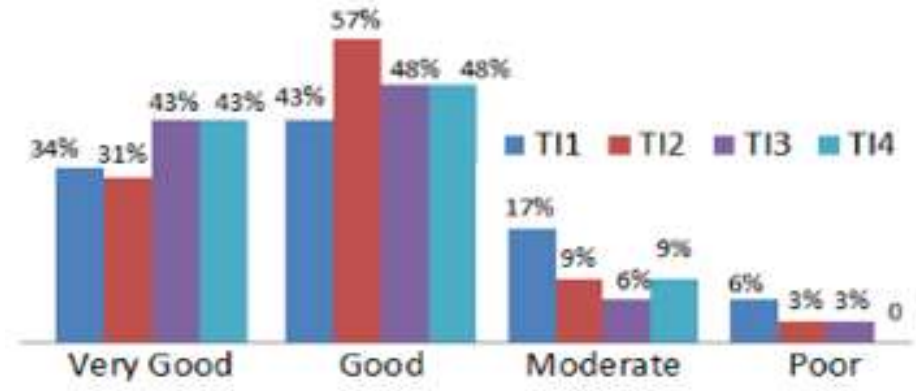

Figure 5. Technology and infrastructure analysis

The internet access for theeast area of Indonesia is one of most critical factors for e-learning implementation. From the results of the evaluation showed that 12 students (34\%) said the internet access in STIKes CHMK very good, 15 students (43\%) say good, 6 students (17\%) say moderate. Only 2students (6\%) said the access to theinternetwas poor.

Beyond campus circumstances, the results showed that 11 students $(31 \%)$ said that their access tothe system out-of-campuswas very good, while 20 students (57\%) stated good and 3 students (9\%) saidmoderate. Only 1 student $(6 \%)$ reported difficulties to access the system outside thecampus. This report indicated that most students can access the system through theinternetfrom their homes and other areas.

From the student perspective, they reported that 15 students(28\%) viewed that the availability of lectures was very good while 17 students and 3 students reported the availability was good and moderate respectively. There is no students complain about the lecture availability which indicates the e-learning implementation in STIKes CHMK was convenient for the lecturers.

For the learning material survey, 15 students (43\%), 17 students (48\%), and 2 students (6\%) reported that the material availability was very good, good, and moderate respectively. Only 1 student (3\%) complaints about the material. The students were able to access the learning material without having to copy or ask from friends or lecturers.

These evaluation results indicate that the access to internet and e-learning system in STIKes CHMK was very good. The students were to access the system through the internet from their homes and other areas. Moreover, the lecturers were available to the students. However, the students expect additional facilities such as video material and more learning materials. Another difficulties is because some students do not have their own laptop and have to find places to access the system. 


\subsection{Content Satisfaction Analysis}

To evaluate the content satisfaction analysis, there are three evaluated aspects in the questioners including: CS1-Suitability of the learning material and the syllabus; CS2-Availability of the learning material to students; CS3-The attractiveness of materials including the content, layout, and error-free. Figure 6 shows graph of content satisfaction analysis.

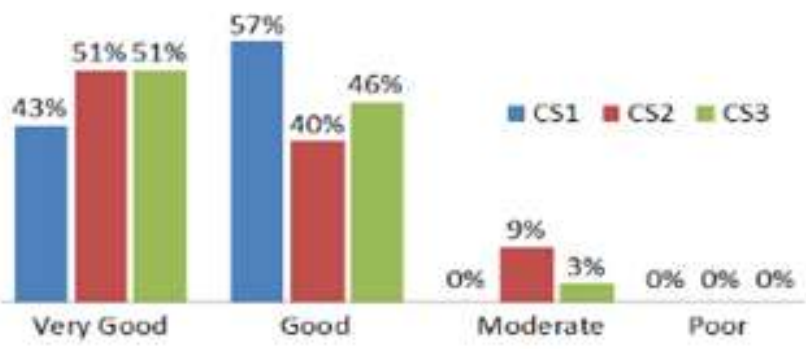

Figure 6. Content satisfaction analysis

The survey showed that only 15 students (43\%) said the content was consistent with the syllabus. However, 20 students (57\%) stated that the content was not aligned with the syllabus. There are two possibilities; first, each lecture tends to use different topic; second, the topic was difficult for the students.

For the learning availability, 18 students (51\%), 14 students (40\%), and 3 students (9\%) reported very well, good, and moderate. No student complaints about the learning availability which mean the prepared material by lecturers were enough for the learning process.

To motivate the students furthermore, the material must be designed with interesting content and good layout. There are 18 students $(51 \%)$ and 16 students $(46 \%)$ stated that the learning material given by lecturers were very good and good respectively. One student stated moderate but no students reported poor.

These results indicated that the materials were interesting enough for the students. They can communicate, interact, and share information between students. According to the students, the design of the material was very easy to understand and can be learned. Besides the students' questioner, we also have asked the lecturers about the system. They have said the students were not very active and tend to follow materials in the system only. Indeed, the lecturers expect the students to be more active.

These results agree with the previous research. Our study has verified that the culture and technological infrastructure in the learning system are the major factors to be considered for student satisfaction. However, we also found that the quality of content also affects the learning process as the students have tendency to depend their studies on the content's quality. These studies is align with previous observed existing factors, such as support, resources, motivation, experience [15], multimedia instruction, interactive learning activities, e-learning system quality [16], student characteristics, technology, impediments [17], and usability aspects [18]. Our study suggests that e-learning system with these factors can also be further enhanced using content factor for better education.

\section{CONCLUSION}

From this study, we found that students in rural areas like in the East Nusa Tenggara Indonesia can follow the new trend in education. E-learning provides an alternative compared to the traditional educational system which is bounded in a confined space like universities and classroom. We have implemented the elearning in an institution located in one of the poorest province in Indonesia. Surprisingly, the students can follow the material and reported that they feel convenient to use the learning management system developed based on Edmodo platform provided that we provide interesting content and design to them. Despite the lack of infrastructure in Kupang city, the students were still able to access and download the learning materials. This indicates that the government of Indonesia need to put more effort in increasing the infrastructure and facilities to support betterinvestment for education through the concept of e-learning. Another study has also been done in Indonesia [18]. However, there are two main limitations in this study. First, they too focused on usability analysis while neglecting the other important aspect of e-learning factors such as technological infrastructure. Secondly, e-Leaning (SceLE) has been used in a university in the Capital City of Indonesia, which has been regarded as the most developed location in the country. It is clearly evident that more studies are in-demand for remote areas with less-developed infrastructure and lack of scholars. Thus, we expect in 
future, the e-learning will be more widely accepted and applied in other provinces as well as other developing countries.

\section{REFERENCES}

[1] Bapenas. Profil Pembangunan Nusa Tenggara Timur, Badan Pusat Statistik (BPS-Statistics Indonesia) Report. 2011.

[2] Mtebe, J. S. (2015). Learning Management System success: Increasing Learning Management system usage in higher education in sub-Saharan Africa. International Journal of Education and Development using Information and Communication Technology; 2015; Vol. 11(2), pp. 51-64.

[3] Salamah I, Ganiardi M. A. Development of E-learning Software Based Multiplatform Components. Bulletin of Electrical Engineering and Informatics. 2017; Vol. 6 (3): pp. 228-234

[4] Romero Tena, R., Cabero Almenara, J., \& Barroso Osuna, J. M. E-Learning of Andalusian University's Lecturers. Gender. TOJET: The Turkish Online Journal of Educational Technology; 2016; Vol. 15 (2); pp. 25-37.

[5] Sfenrianto, Hasibuan Z. A. Step-Function Approach for E-Learning Personalization. TELKOMNIKA. 2017; Vol.15 (3): pp. 1362-1367

[6] Enriquez M. A. S. Students. Perceptions on the Effectiveness of the Use of Edmodo as a Supplementary Tool for Learning. DLSU Research Congress. 2014; pp. 6-11.

[7] Batsila M, Tsihouridis C, Vavougios D. Entering the web-2 edmodo world to support learning: Tracing teachers' opinion after using it in their classes. International Journal of Emerging Technologies in Learning. 2014; 9(1): pp. $53-60$.

[8] Lim H, Lee S, G, Nam K. Validating E-learning factors affecting training effectiveness. International Journal of Information Management. 2007; 27(1): pp. 22-35.

[9] Olaniran B. A. Discerning culture in E-Learning and in the global workplaces. Knowledge Management and ELearning. 2009; 1(3): pp. 180-195.

[10] Ali G. E, Magalhaes R. Barriers to implementing e-learning: A Kuwaiti case study. International Journal of Training and Development. 2008;12(1): pp. 36-53.

[11] Pocatilu P, Alecu F, Vetrici M. Using Cloud Computing for E-learning Systems 2 Cloud Computing. WSEAS Transactions on Computers. 2010; Vol. 9(1): pp. 42-51.

[12] Selim H. M. Critical success factors for e-learning acceptance: Confirmatory factor models. Computers \& Education. 2007; Vol. 49(2): pp. 396-413.

[13] Wu J. H, Tennyson R. D, Hsia T. L. A study of student satisfaction in a blended e-learning system environment. Computers \& Education. 2010; Vo. 55(1): pp. 155-164.

[14] ikSfenrianto, Hasibuan, Z.A., Suhartanto, H., Selviandro, N. An Approach to Detect Learning Types Based on Triple-Factor In eLearning Process. Journal of Next Generation Information Technology, 2014; Vol. 5(1), pp. 9-15.

[15] Noesgaard S. S, Ørngreen R. The effectiveness of e-learning: an explorative and integrative review of the definitions, methodologies and factors that promote e-learning effectiveness. Electronic Journal of e-Learning. 2015; Vol. 13(4): 278-290.

[16] Aparicio, M., Bacao, F., \& Oliveira, T. (2016). Cultural impacts on e-learning systems' success. The Internet and Higher Education, 2016; Vol. 31, pp. 58-70.

[17] Alakklouk S. A. The Factors Influencing the Effectiveness of e-Learning at Al-Quds Open University in Palestine. Master dissertation: Universiti Utara Malaysia; 2012.

[18] Junus I. S, Santoso H. B, Isal R. Y. K, Utomo A. Y. Usability evaluation of the student centered e-learning environment. The International Review of Research in Open and Distributed Learning. 2015; Vol. 16(4).

[19] Golband F, Hosseini A. F, Mojtahedzadeh R, Mirhosseini F, Bigdeli S. The correlation between effective factors of E-learning and demographic variables in a post-graduate program of virtual medical education in tehran university of medical sciences. Acta Medica Iranica. 2014; Vol. 52(11).

[20] Sensuse D. I, Napitupulu D. B. The Study of User Acceptance toward E-Learning System in Higher Education. Indonesian Journal of Electrical Engineering and Computer Science (IJEECS). 2017; Vol. 7(2): pp. 466-473. 